\title{
Nutrition des veaux au cours du sevrage. II. - Quelques aspects de l'utilisation digestive et métabolique des protéines
}

\author{
par K.G. KOUAME (1), P. PATUREAU-MIRAND, J.L. TROCCON *, \\ J. PRUGNAUD, M. JOURNET * et R. PION \\ avec la collaboration technique de Françoise Barre, G. Bayle, Odile Bernard, \\ M. Sallas, A. Selle et Marie-Claude Valluy \\ I.N.R.A., Laboratoire d'Etudes du Métabolisme azoté (2) \\ Centre de Recherches de Theix, $F 63122$ Ceyrat \\ * I.N.R.A., Station de Recherches sur la Vache laitière \\ Centre de Recherches de Rennes, Saint-Gilles, F 35590 L'Hermitage
}

\begin{abstract}
Résumé
L'évolution de l'état de nutrition azotée pendant les semaines qui précèdent ou suivent immédiatement le sevrage des 16 veaux femelles des 2 essais décrits précédemment (Kouame et al., 1984) est étudiée par l'examen des variations des teneurs en urée et acides aminés libres du sang. Ces animaux sont sevrés à 6 semaines et reçoivent ad libitum dès le début de chaque essai des aliments concentrés différant par leur teneur en matières azotées (p. 100 de la matière sèche : 16,4 et 20,4 pour les aliments $A$ et $B$ de l'essai $1 ; 14,8$ et 17,4 pour les aliments $\mathrm{C}$ et $\mathrm{D}$ de l'essai 2). Des informations complémentaires sur l'évolution de la digestion ruminale et intestinale pendant cette période ont été recherchées au cours de l'essai 2 par l'analyse de la composition en acides aminés des contenus de duodénum et des fèces de 2 veaux munis d'une canule simple du duodénum.

Le sevrage modifie profondément la composition en acides aminés des contenus du duodénum de ces 2 veaux; elle tend à se rapprocher de celle des bactéries du rumen après le sevrage alors qu'elle est voisine de celle du lait avant. Parmi les protéines de l'orge, les hordéines paraissent particulièrement dégradées dans les estomacs; en revanche, les protéines du mélange de tourteaux traités au formaldéhyde semblent peu dégradées et augmentent la fourniture d'acides aminés à l'organisme. L'urémie qui varie peu jusqu'à une semaine après le sevrage, diminue par la suite; elle est plus élevée chez les animaux qui ingèrent les aliments concentrés les plus riches en matières azotées; ses variations dépendent des quantités de PDI et énergie métabolisable ingérées. Les teneurs en acides aminés indispensables du sang diminuent pendant la période du sevrage, à l'exception de celles en valine et isoleucine. Elles sont généralement plus élevées chez les animaux qui consomment les aliments concentrés les plus riches en protéines. Les teneurs sanguines en lysine, méthionine, leucine et tyrosine libres paraissent être très étroitement liées au flux de ces composés dans l'intestin et à la quantité d'énergie métabolisable ingérée. La lysine et la méthionine semblent être les principaux acides aminés limitants pendant cette période. Les teneurs sanguines en proline et glycine libres varient au cours du sevrage dans le même sens que les concentrations de ces composés dans les contenus de duodénum.
\end{abstract}

Mots clés : sevrage, veau, protéine alimentaire, digestion, métabolisme azoté.

(1) Adresse actuelle : Université Nationale de Côte-d'Ivoire, Faculté des Sciences : Laboratoire de Physiologie Animale et de Psychophysiologie 04, B.P. 32:2, Abidjan 04, R.C.I.

(2) Les demandes de tirés à part devront être envoyées à cette adresse. 


\section{Introduction}

Dans l'article précédent (Kounme et al., 1984), nous avons montré par l'étude des variations de la consommation alimentaire, de la croissance et des concentrations sanguines en divers nutriments caractéristiques du métabolisme énergétique (glucose, acétate, $\beta$ hydroxybutyrate et acides gras non estérifiés) que, pendant la période de sevrage, des veaux femelles sevrés à 6 semaines subissent une carence énergétique bien qu'ils soient nourris à volonté. Dans cet article, nous tenterons de préciser l'évolution de l'état de nutrition azotée des mêmes veaux pendant cette période par l'examen des variations de l'urémie et de l'aminoacidémie. De plus, une étude de la composition des contenus de duodénum a fourni quelques informations sur l'évolution de la digestion des matières azotées dans le rumen, susceptibles de faciliter l'interprétation des variations des paramètres sanguins mesurés.

\section{Matériel et méthodes}

\section{A. Conduite de l'expérience et prélèvements}

Le schéma expérimental a été décrit en détail dans la publication précédente (Kouame et al., 1984). Seuls vont être rappelés ici les principaux aspects des conditions expérimentales ainsi que ceux qui sont spécifiques de cette étude.

Deux essais ont été réalisés à l'aide de 16 veaux femelles de type pie noir, répartis en 2 lots de 4 animaux dans chaque essai [en fait, 3 animaux dans le lot $\mathrm{A}$ de l'essai 1 (Kounme et al., 1984)]. Le deuxième essai a été complété par une étude de l'évolution de la composition des contenus de duodénum et des fèces au cours du sevrage à l'aide de 2 veaux mâles. Lors de chacun des essais, 2 aliments concentrés (A ou $\mathrm{B}$ dans l'essai 1, C ou D dans l'essai 2) sont distribués à l'un des 2 lots. Ces aliments concentrés diffèrent par leur teneur en matières azotées et la nature de ces dernières; les aliments $\mathrm{B}$ et $\mathrm{D}$ dérivent respectivement des aliments $\mathrm{A}$ et $\mathrm{C}$ par substitution à une quantité équivalente d'orge, d'un mélange de tourteaux de colza et de soja traité au formaldéhyde pour le rendre moins dégradable dans le rumen. La composition des aliments (lait, concentrés, foin) est rapportée dans le tableau 1. Les niveaux d'ingestion de ces aliments sont décrits en détail dans la publication précédente.

Le logement des veaux, le mode de sevrage (effectif à 6 semaines) et d'alimentation ainsi que le protocole des prélèvements de sang sont décrits dans la publication citée ci-dessus.

Les prélèvements de contenus du duodénum et de fèces sont effectués sur 2 veaux mâles munis de canules simples implantées à $10 \mathrm{~cm}$ environ du pylore, aux âges respectifs de 10 et 13 jours. La collecte des contenus de duodénum et de fèces de 2 veaux destinés à recevoir soit l'aliment $C$ soit l'aliment $D$ et nourris selon le protocole adopté pour les femelles, commence une quinzaine de jours après l'opération. La procédure utilisée est voisine de celle décrite par Poncet \& RaYssi- 


\section{Tableav 1}

Composition des aliments.

Feed composition.

\begin{tabular}{|c|c|c|c|c|c|c|}
\hline \multirow[b]{3}{*}{$\begin{array}{l}\text { Matières azotées }(\mathrm{N} \times 6,25 \text { p. } 100 \mathrm{~g} \\
\text { MS) } \ldots \ldots \ldots \ldots \ldots \ldots \ldots \ldots \ldots \cdots \cdots \\
\text { Crude protein }\end{array}$} & \multirow{3}{*}{$\begin{array}{c}\text { Lait } \\
\text { Milk } \\
\end{array}$} & \multicolumn{4}{|c|}{$\begin{array}{l}\text { Aliments concentrés (1) } \\
\text { Concentrates }\end{array}$} & \multirow{3}{*}{$\begin{array}{l}\text { Foin } \\
\text { Hay }\end{array}$} \\
\hline & & A & B & $\mathrm{C}$ & $\mathrm{D}$ & \\
\hline & & 16,4 & 20,4 & 14,8 & $17: 4$ & \\
\hline $\begin{array}{l}\mathrm{N} \text { soluble p. } 100 \mathrm{~N} \text { total } \ldots \ldots \ldots \ldots \\
N \text { solubility p. } 100\end{array}$ & - & 45 & 33 & 38 & 30 & - \\
\hline PDI (g p. 100 g MS) (2) & - & 10,7 & 14,0 & 9,7 & 12,6 & 5,6 \\
\hline $\begin{array}{l}\text { Energie métabolisable }{ }^{(3)}(\mathrm{kcal} \text { p. } 100 \\
\text { g MS }) \ldots \ldots \ldots \ldots \ldots \ldots \ldots \ldots \ldots \ldots \\
\text { Metabolizable energy }\end{array}$ & 474 & 280 & 277 & 282 & 279 & 258 \\
\hline $\begin{array}{l}\text { Acides aminés ( }(\mathrm{g} \text { p. } 16 \mathrm{~g} \mathrm{~N}) \ldots \ldots \\
\text { Amino acids }\end{array}$ & & & & & & \\
\hline A. aspartique $\ldots \ldots \ldots \ldots \ldots \ldots$ & 7,75 & 7,30 & 8,05 & 4,75 & 6,60 & 10,10 \\
\hline Thréonine $\ldots \ldots \ldots \ldots$ & 4,60 & 2,70 & 3,05 & 2,65 & 3,25 & 4,30 \\
\hline Sérine $\ldots \ldots \ldots \ldots \ldots \ldots \ldots \ldots$ & 5,75 & 4,20 & 4,30 & 3,40 & 4,20 & 4,65 \\
\hline A. glutamique $\ldots \ldots \ldots \ldots \ldots \ldots$ & 20,25 & 18,65 & 17,30 & 19,65 & 19,60 & 10,20 \\
\hline Proline $\ldots \ldots \ldots \ldots \ldots \ldots \ldots$ & 9,75 & 7,80 & 6,65 & 8,60 & 7,75 & 5,95 \\
\hline Glycine $\ldots \ldots \ldots \ldots \ldots$ & 2,00 & 4,25 & 4,50 & 3,15 & 3,60 & 4,80 \\
\hline Alanine $\ldots \ldots \ldots \ldots \ldots \ldots \ldots$ & 3,50 & 3,55 & 4,15 & 325 & 3,65 & 5,55 \\
\hline Valine $\quad \ldots \ldots \ldots \ldots \ldots \ldots \ldots$ & 6,65 & 3,60 & 4,05 & 3,90 & 4,35 & 4,70 \\
\hline Cystine & 1,70 & 2,20 & 2,10 & 2,25 & 2,25 & 1,95 \\
\hline Méthionine $\ldots \ldots \ldots \ldots \ldots$ & 2,80 & 1.50 & 1,60 & 1,30 & 1,50 & 1,65 \\
\hline Isoleucine $\ldots \ldots \ldots \ldots \ldots \ldots \ldots$ & 5,35 & 3,00 & 3,35 & 3,05 & 3,65 & 4,35 \\
\hline Leucine $\ldots \ldots \ldots \ldots$. & 9,35 & 5,50 & 6,10 & 5.20 & 6,00 & 7,00 \\
\hline Tyrosine $\ldots \ldots \ldots \ldots \ldots \ldots \ldots$ & 5,25 & 2,70 & 2,90 & 2,45 & 2,80 & 3,55 \\
\hline Phénylalanine $\ldots \ldots \ldots \ldots \ldots$ & 4,50 & 4,30 & 4,40 & 3,80 & 4,05 & 3,75 \\
\hline Lysine . . . . . & 7,95 & 3,15 & 3,70 & 2,65 & 3,60 & 5,25 \\
\hline Histidine $\ldots \ldots \ldots \ldots \ldots \ldots \ldots$ & 2,70 & 2,30 & 2,40 & 1,60 & 2,10 & 2,05 \\
\hline Arginine $\quad \ldots \ldots \ldots \ldots \ldots \ldots \ldots$ & 3,40 & 5,90 & 6,15 & 3,75 & 4,80 & 4,55 \\
\hline
\end{tabular}

(1) Pour plus de détails, voir Kouame et al. (1984). More details in Kouame et al. (1984).

(2) Teneur en protéines digestibles dans l'intestin (PDI) des aliments concentrés déterminée à partir de leur concentration en azote soluble selon la méthode décrite par l'I.N.R.A. (1978); pour le foin la valeur adoptée est celle fournie par les tables (I.N.R.A., 1978).

The digestible protein content in the small intestine (PDI) of the concentrates was calculated according to their soluble nitrogen content as described by I.N.R.A. (1978); the PDI content of hay was obtained by referring to the feed tables (I.N.R.A., 1978).

(3) Teneur en énergie métabolisable estimée à partir de celles des différents aliments et constituants des aliments concentrés rapportées dans les tables (I.N.R.A., 1978).

The metabolizable energy contents of the feed and of their constituents was obtained by referring to the feed tables (I.N.R.A., 1978). 
GUIER (1980); elle consiste en 12 prélèvements consécutifs toutes les 4 heures, également répartis au cours des troisième et quatrième jours de chacune des 3 semaines précédant ou suivant le sevrage réalisé à 63 jours pour le veau consommant l'aliment concentré $C$ et 56 jours pour l'autre. Les contenus de duodénum $(40 \mathrm{~g})$ et les fèces $(20 \mathrm{~g})$ recueillis à chaque prélèvement sont homogénéisés puis conservés à $-15^{\circ} \mathrm{C}$ dans un récipient contenant les échantillons prélevés dans les heures précédentes de façon à constituer, pour chaque veau, un échantillon moyen lors de chaque semaine.

\section{B. Analyses}

\section{Contenus digestifs, fèces et aliments}

La teneur en matière sèche des contenus de duodénum et des fèces est assimilée à celle en produit lyophilisé ; celle des aliments est déterminée par dessication à l'étuve $\left(70^{\circ} \mathrm{C}\right)$ pendant 48 heures. Les teneurs en matières azotées totales $(\mathrm{N} \times 6,25)$ des aliments, des contenus de duodénum et des fèces sont mesurées par la méthode Kjeldhal. Leur composition en acides aminés est déterminée par chromatographie sur résine échangeuse d'ions après 3 hydrolyses acides des échantillons $(24 \mathrm{~h}$, $48 \mathrm{~h}, 24 \mathrm{~h}$ précédée d'une oxydation performique) selon la méthode décrite par Prugnaud \& Pion (1976). Le dosage de l'acide diaminopimélique a été réalisé sur les échantillons ayant subi l'oxydation performique préalable à l'hydrolyse de $24 \mathrm{~h}$ selon la méthode de MziK et al. (1978).

\section{Urée et acides aminés libres du sang}

L'urée sanguine est dosće selon la méthode à la diacétylmonoxime sur chaque échantillon prélevé. Les teneurs en acides aminés libres du sang jugulaire sont mesurées sur les échantillons moyens constitués pour chaque veau par le mélange des 7 prélèvements (essai 1) ou 3 prélèvements (essai 2) effectués au cours de la journée. Ces concentrations sont déterminées par chromatographie sur résine échangeuse d'ions après extraction à l'éthanol $\left(82^{\circ}\right)$ additionnée de thiodiglycol (2 p. 100) (PAWLAK \& PION, 1968).

\section{Analyse statistique des résultats}

La comparaison des moyennes 2 à 2 a été réalisée à l'aide du test « $\mathrm{t}$ » de Student et les relations entre les diverses variables ont été établies par régression linéaire multiple (SNEDECOR \& COCHRAN, 1971). L'évolution de la composition en acides aminés des matières azotées des contenus de duodénum et des fèces a été décrite par une analyse factorielle des correspondances (LEBART \& FínELON, 1973) et le calcul de la distance du $\chi^{2}$ (Guilloteau, Sauvant \& Patureau-Mirand, 1983).

\section{Résultats}

\section{A. Evolution de la composition des contenus de duodénum}

Leurs teneurs en matières azotées totales (tabl. 2) tendent à être plus élevées après le sevrage qu'avant, chez le veau qui reçoit l'aliment $\mathrm{C}$; c'est l'inverse 
TABleau 2

Composition en acides aminés des contenus de duodénum.

Amino acid composition of duodenal contents.

\begin{tabular}{|c|c|c|c|c|}
\hline $\begin{array}{c}\text { Aliments concentrés } \\
\text { Concentrates }\end{array}$ & \multicolumn{2}{|c|}{$\mathrm{C}$} & \multicolumn{2}{|c|}{$\mathbf{D}$} \\
\hline Périodes & $\begin{array}{c}\text { Avant } \\
\text { sevrage (1) }\end{array}$ & $\begin{array}{c}\text { Après } \\
\text { sevrage (1) }\end{array}$ & $\begin{array}{c}\text { Avant } \\
\text { sevrage }\end{array}$ & $\begin{array}{l}\text { Après } \\
\text { After }\end{array}$ \\
\hline Periods & $\begin{array}{l}\text { Before } \\
\text { weaning }\end{array}$ & $\begin{array}{c}\text { After } \\
\text { weaning }\end{array}$ & $\begin{array}{l}\text { Before } \\
\text { weaning }\end{array}$ & $\begin{array}{l}\text { sevrage } \\
\text { weaning }\end{array}$ \\
\hline $\begin{array}{l}\text { Matières azotées }(\mathrm{gN} \times 6,25 \mathrm{p} .100 \mathrm{~g} \mathrm{MS}) \\
\text { Crude protein }(\mathrm{gN} \times 6.25 \text { p. } 100 \mathrm{~g} \mathrm{DM})\end{array}$ & $26,77^{\mathrm{ac}}$ & $31,83^{b}$ & $28,92^{a b}$ & $24,77^{\mathrm{c}}$ \\
\hline $\begin{array}{l}\text { Acides aminés } \ldots \ldots \ldots \ldots \ldots \ldots \ldots \\
\text { Amino acids }\end{array}$ & $99,50^{\mathrm{a}}$ & $83,30^{\mathrm{b}}$ & $102,75^{\mathrm{a}}$ & $86,75^{b}$ \\
\hline 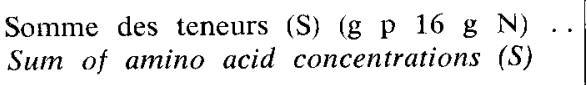 & & & & \\
\hline A. aspartique (p. $100 \mathrm{~S}) \ldots \ldots \ldots \ldots$ & $8,50^{\mathrm{a}}$ & $10,73^{b}$ & $8,48^{\mathrm{a}}$ & $10,95^{b}$ \\
\hline Thréonine $\ldots \ldots \ldots \ldots \ldots \ldots \ldots$ & 4,67 & 4,89 & 4,63 & 4,92 \\
\hline Sérine $\ldots \ldots \ldots \ldots \ldots \ldots \ldots \ldots \ldots \ldots$ & $5,68^{\mathrm{a}}$ & $5,06^{\mathrm{b}}$ & $5,67 \mathrm{a}$ & $5,26^{b}$ \\
\hline A. glutamique $\ldots \ldots \ldots \ldots \ldots \ldots$ & $18,46^{\mathrm{a}}$ & $16,16^{\mathrm{b}}$ & $18,72^{a}$ & $16,19 b$ \\
\hline Proline $\ldots \ldots \ldots \ldots \ldots \ldots \ldots \ldots \ldots \ldots \ldots \ldots \ldots \ldots$ & $8,31^{\mathrm{a}}$ & $5,00^{b}$ & $8,28^{\mathrm{a}}$ & $5,48^{b}$ \\
\hline Glycine $\ldots \ldots \ldots \ldots \ldots \ldots \ldots \ldots \ldots$ & $2,91^{a}$ & $5,91^{\mathrm{b}}$ & $2,78^{a}$ & $5,05^{\mathrm{b}}$ \\
\hline Alanine $\ldots \ldots \ldots \ldots \ldots \ldots \ldots \ldots \ldots$ & $4,26^{\mathrm{a}}$ & $6,21^{b}$ & $4,04^{a}$ & $6,09^{b}$ \\
\hline$\ldots \ldots \ldots \ldots \ldots \ldots \ldots \ldots \ldots$ & $5,83 \mathrm{a}$ & $5,77^{\mathrm{ab}}$ & $6,22^{a}$ & $5,74^{b}$ \\
\hline Cystine $\ldots \ldots \ldots \ldots \ldots \ldots \ldots \ldots \ldots$ & $1,70^{\mathrm{a}}$ & $1,94 \mathrm{a}$ & $1,57 \mathrm{a}$ & $2,30^{b}$ \\
\hline Méthionine $\ldots \ldots \ldots \ldots \ldots \ldots \ldots$ & $2,18^{a}$ & $1,68^{\mathrm{a}}$ & $2,23^{a}$ & $1,60^{\mathrm{b}}$ \\
\hline Isoleucine $\ldots \ldots \ldots \ldots \ldots \ldots \ldots \ldots$ & 4,86 & 4,84 & 5,14 & 5,02 \\
\hline Leucine $\ldots \ldots \ldots \ldots \ldots \ldots \ldots$ & 8,47 a & $7,48^{b}$ & $8,67 \mathrm{a}$ & $7,40^{\mathrm{b}}$ \\
\hline Tyrosine & 5,42 & 5,19 & 4,93 & 5,62 \\
\hline Phénylalanine $\ldots \ldots \ldots \ldots \ldots \ldots \ldots$ & 4,75 & 4,54 & 4,45 & 4,29 \\
\hline Lysine $\ldots \ldots \ldots \ldots \ldots \ldots \ldots$ & $7,63^{\mathrm{a}}$ & $6,96^{\mathrm{b}}$ & $7,54^{\mathrm{a}}$ & $6,77^{b}$ \\
\hline Histidine $\ldots \ldots \ldots \ldots \ldots \ldots \ldots$ & 2,54 & 2,32 & 2,64 & 2,39 \\
\hline Arginine $\ldots \ldots \ldots \ldots \ldots \ldots \ldots \ldots$ & $3,84^{a}$ & $5.35^{b}$ & $4,02^{a}$ & $5,68^{b}$ \\
\hline A. diaminopimélique (g p 16 g N) & $0.18^{\mathrm{a}}$ & $0,56^{b}$ & $0,10^{\mathrm{a}}$ & $0,35^{\mathrm{c}}$ \\
\hline
\end{tabular}

(1) Valeur moyenne correspondant aux échantillons prélevés au cours des 3 semaines qui précèdent ou suivent le sevrage.

Mean values of the concentrations measured during the 3 weeks before or after weaning.

a, b, c : Les valeurs d'une même ligne affectées d'un même indice ne sont pas significativement différentes $(P>0,05)$.

Values on the same line sharing a common subscript are not significantly different $(P>0.05)$. 


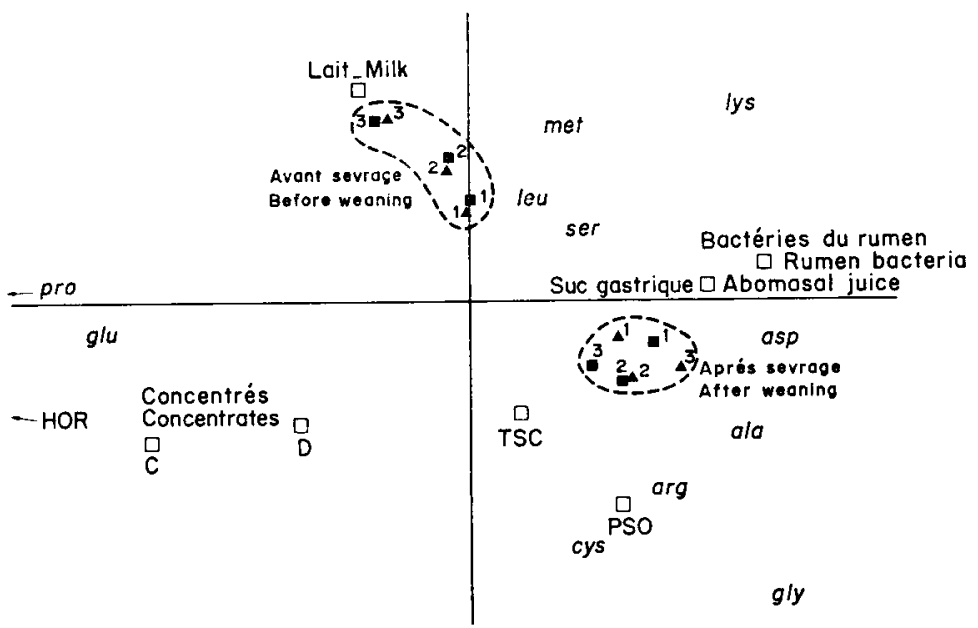

FIG. 1

Comparaison des compositions en acides aminés des contenus de duodénum à celles des matières azotées alimentaires, endogènes et bactériennes (plan principal de l'analyse factorielle des correspondances : 91,2 p. 100 de la variance).

Comparison between the amino acid composition of duodenal contents and dietary, endogenous and bacterial proteins

(principal plane of the factorial correspondence analysis : $91.2 \mathrm{p} .100$ of variance).

A Contenus de duodénum des veaux recevant respectivement les aliments C et D (les numéros sont ceux des semaines avant ou après le sevrage).

Duodenal contents of the calves fed concentrates $C$ and $D$ respectively (numbers are those of the weeks before or after weaning).

Matières azotées bactériennes, endogènes ou alimentaires :

Bacterial, endogenous or dietary proteins :

Bactéries du rumen (PION \& FAUCONNEAU, 1968) - Rumen bacteria.

Suc gastrique (Guilloteau, Sauvant \& Patureau-Mirand, 1983) - Abomasal juice.

TSC : Mélange de tourteaux de colza et de soja traités au formaldéhyde. Mixture of formaldehyde treated rapeseed and soyabean meals.

HOR : Hordéines (Lauriere, Charbonnier \& Mosse, 1976) - Hordeins.

PSO : Protéines de l'orge ayant la composition en acides aminés des protéines salinosolubles (Landry, MoureauX \& HUeT, 1972).

Barley proteins with the same amino acid composition as barley salinosoluble proteins (LANDRY, MOUREAUX \& HUeT, 1972).

lys : Projection de quelques-uns des 17 acides aminés sur le plan principal. Projection on the principal plane of some amino acids among the 17 used for the factorial correspondence analysis. 
chez le veau nourri avec l'aliment $\mathrm{D}$. La somme des teneurs en acides aminés, mesurée dans les contenus duodénaux, est moins forte après le sevrage qu'avant. Il y a peu de différences entre les 2 veaux. La composition en acides aminés de ces digesta qui évolue assez peu au cours des 3 semaines qui précèdent le sevrage, est nettement modifiée par le sevrage (fig. 1). Les acides aminés dont les teneurs augmentent après le sevrage sont l'acide aspartique, la glycine, l'alanine, la cystine et l'arginine ; ceux dont les teneurs baissent sont la proline, la méthionine, la leucine, la lysine, l'acide glutamique et la sérine (tabl, 2). La nature de l'aliment concentré ne semble pas avoir d'influence significative sur la composition en acides aminés des contenus. En revanche, les teneurs en acide diaminopimélique des matières azotées des contenus de duodénum sont plus faibles chez le veau recevant l'aliment $\mathrm{D}$ que chez l'autre animal. Dans les 2 cas, elles sont plus faibles avant le sevrage qu'après (tabl. 2).

L'équilibre en acides aminés indispensables et semi-indispensables des protéines de ces contenus a été caiculé selon la méthode proposée par Pion, DE BELSUnCE \& Fauconneau (1963) (tabl. 3). Selon cette méthode, lorsque la teneur en un acide aminé indispensable ou semi-indispensable d'une protéine excède notablement les besoins, seule une fraction de l'apport permet de satisfaire le besoin spécifique en ce composé. Les teneurs en acides aminés excédentaires utilisées pour le calcul de l'équilibre en acides aminés indispensables ont donc été corrigées selon les recommandations de ces auteurs ; une restriction concernant les teneurs en cystine des protéines des contenus y a été ajoutée puisque ces dernières en sont riches et que pour être utile, l'apport de cystine ne doit pas dépasser 50 p. 100 de l'apport total des acides aminés soufrés (Patureau-Mirand et al., 1973). Calculé dans ces conditions, l'équilibre en acides aminés indispensables des protéines des contenus de duodénum varie peu d'une semaine à l'autre quel que soit le lot. De plus, il est voisin entre les 2 lots quelle que soit la semaine considérée.

\section{B. Composition des fèces}

Les teneurs en matières azotées des fèces tendent à être légèrement plus élevées dans les fèces du veau qui consomme l'aliment concentré $\mathrm{D}$ que dans celles de l'autre veau (tabl. 4). Les concentrations en acides aminés des fèces sont très voisines avant et après sevrage et quel que soit l'aliment concentré distribué. Seules les teneurs en sérine, cystine et arginine sont significativement moins élevées après le sevrage alors que celles en alanine sont plus fortes. L'influence de la nature des matières azotées des aliments concentrés sur la composition en acides aminés des fèces ne se manifeste que sur les teneurs en leucine qui sont significativement plus élevées chez le veau nourri avec l'aliment $\mathrm{D}$ tandis que celles en alanine tendent à être plus fortes chez le veau recevant l'aliment $\mathrm{C}$.

\section{Evolution de l'urémie et de l'aminoacidémie au cours du sevrage}

\section{Urémie}

L'évolution de l'urémie des veaux des essais 1 et 2 en fonction de l'heure après distribution des aliments et de l'âge est représentée sur la figure 2. Dans l'essai 1, après le sevrage, les teneurs sanguines en urée ont tendance à être plus faibles à partir de la cinquième heure après la distribution des aliments solides que 


\section{TABLeaU 3}

Equilibre en acides aminés indispensables et semi indispensables dans les contenus de duodénum ( $p .100$ de la somme corrigée (1)).

Essential and semi essential amino acid balance in the duodenal contents (p. 100 of the corrected sum(1)).

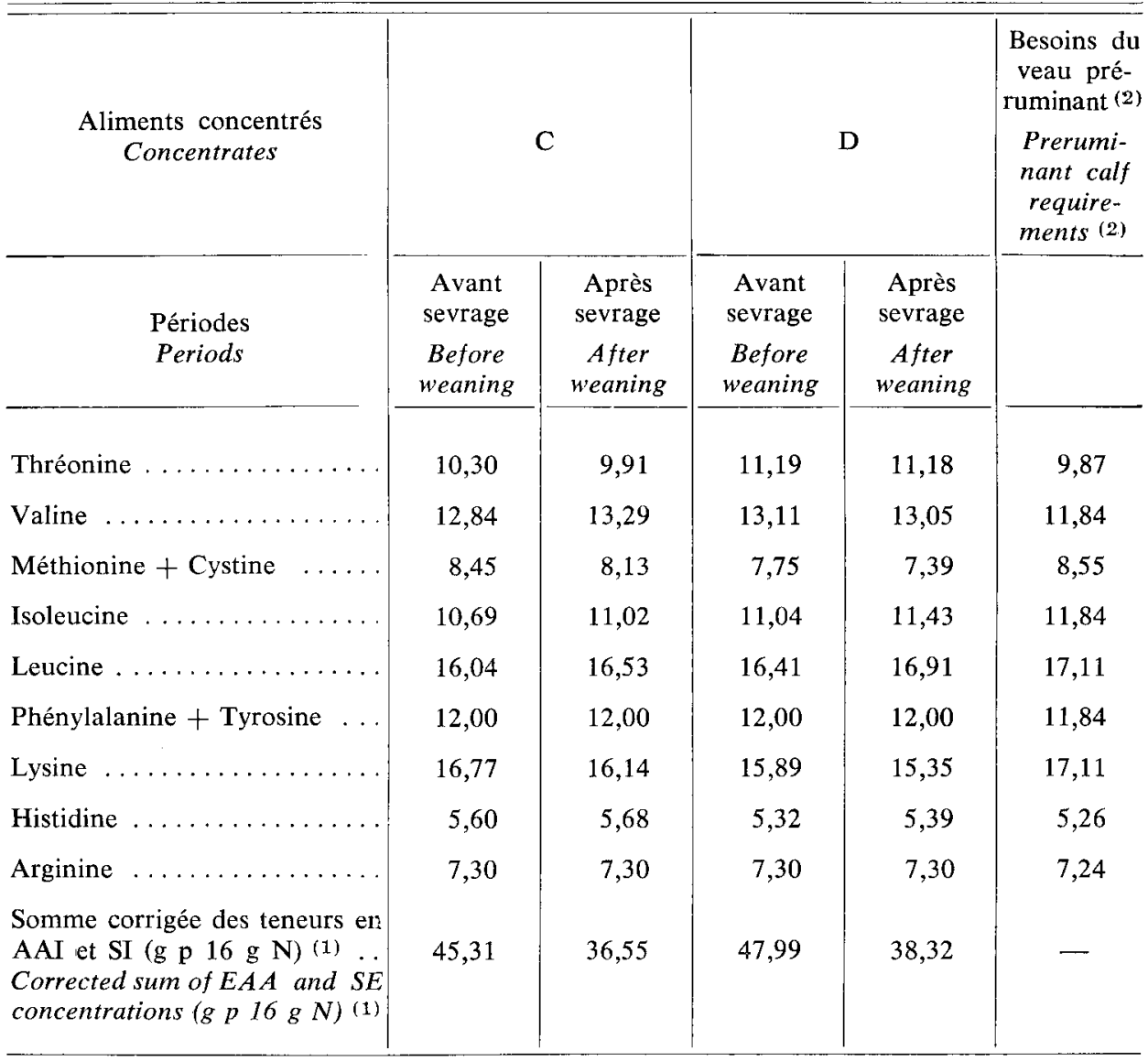

(1) Teneurs en cystine et en leucine limitées respectivement à 1 fois et 1,5 fois celles en méthionine et en isoleucine; teneurs en tyrosine + phénylalanine et en arginine limitées respectivement à 12 et 7,3 p. 100 de la somme corrigée des teneurs (PION, DE Belsunce et Fauconneau, 1963). Cystine and leucine levels represented 1 and 1.5 times respectively those of methionine and isoleucine; tyrosine + phenylalanine and arginine were limited to 12 and $7.3 \mathrm{p} .100$ respectively of the corrected sum (Pion, de Belsunce and Fauconneau, 1963).

(2) Patureau-Mirand et al. (1974) ; Patureau-Mirand et al. (1980) pour 1'histidine; PatureauMirand (non publié) pour la thréonine. 
TABleaU 4

Composition en acides aminés des fèces.

Amino acid composition of faeces.

\begin{tabular}{|c|c|c|c|c|}
\hline \multirow{2}{*}{\begin{tabular}{l}
\multicolumn{2}{c}{$\begin{array}{c}\text { Aliments concentrés } \\
\text { Concentrates }\end{array}$} \\
Périodes $\ldots \ldots \ldots \ldots \ldots \ldots \ldots \ldots \ldots \ldots \ldots$ \\
Periods
\end{tabular}} & \multicolumn{2}{|c|}{$\mathrm{C}$} & \multicolumn{2}{|c|}{$\mathrm{D}$} \\
\hline & $\begin{array}{l}\text { Avant } \\
\text { sevrage (1) } \\
\text { Before } \\
\text { weaning }\end{array}$ & $\begin{array}{l}\text { Après } \\
\text { sevrage (1) } \\
\text { After } \\
\text { weaning }\end{array}$ & $\begin{array}{l}\text { Avant } \\
\text { sevrage } \\
\text { Before } \\
\text { weaning }\end{array}$ & $\begin{array}{l}\text { Après } \\
\text { sevrage } \\
\text { After } \\
\text { weaning }\end{array}$ \\
\hline $\begin{array}{l}\text { Matières azotées }(\mathrm{g} \mathrm{N} \times 6,25 \mathrm{p} .100 \mathrm{~g} \mathrm{MS}) \\
\text { Crude protein }(g N \times 6.25 \mathrm{p} .100 \mathrm{~g} \mathrm{DM}) \\
\begin{array}{l}\text { Acides aminés } \ldots \ldots \ldots \ldots \ldots \ldots \ldots \\
\text { Amino acids }\end{array}\end{array}$ & 19,37 & 19,23 & 23,94 & 23,50 \\
\hline $\begin{array}{l}\text { Somme des teneurs }(\mathrm{S})(\mathrm{g} \text { p. } 16 \mathrm{~g} \\
\text { Sum of amino acid concentrations }\end{array}$ & 89,40 & 87,23 & 91,33 & 86,00 \\
\hline A. aspartique (p. $100 \mathrm{~S}$ ) & 10,86 & 10,89 & 10,62 & 10,69 \\
\hline Thréonine & 5,29 & 5,35 & 5,54 & 5,25 \\
\hline Sérine $\ldots \ldots \ldots \ldots \ldots \ldots$ & $5,89^{\mathrm{a}}$ & $5,37 \mathrm{~b}$ & $5,60^{\mathrm{ab}}$ & $5,35^{b}$ \\
\hline A. glutamique & 14,54 & 13,73 & 13,92 & 14,41 \\
\hline Proline $\ldots \ldots$. & 4,96 & 4,90 & 4,98 & 4,51 \\
\hline Glycine $\ldots \ldots \ldots \ldots \ldots \ldots$ & 5,30 & 5,55 & 5,78 & 5,63 \\
\hline Alanine ... . & $6,91^{\mathrm{a}}$ & $7,28^{\mathrm{ab}}$ & $5,83^{\mathrm{c}}$ & $6,56^{\mathrm{ab}}$ \\
\hline Valine ... & 5,85 & 6,21 & 5,63 & 6,05 \\
\hline$\ldots \ldots \ldots$ & $3,56^{\mathrm{a}}$ & $2,51^{\mathrm{b}}$ & $3,31^{\mathrm{a}}$ & $2,91^{\mathrm{b}}$ \\
\hline Méthionine $\quad \ldots \ldots \ldots \ldots \ldots \ldots \ldots$ & 2,31 & 2,31 & 2,46 & 2,39 \\
\hline Isoleucine $\quad \ldots \quad \ldots \quad \ldots \ldots \ldots$. & 4,72 & 4,77 & 4,29 & 4,89 \\
\hline Leucine $\ldots \ldots \ldots \ldots \ldots \ldots$ & $7,04^{\mathrm{a}}$ & $7,19 a$ & $7,87^{b}$ & $7,71^{b}$ \\
\hline Tyrosine $\ldots \ldots \ldots \ldots \ldots \ldots \ldots$ & 4,21 & 4,86 & 4,40 & 4,29 \\
\hline Phénylalanine & 4,08 & 4,82 & 4,79 & 4,79 \\
\hline Lysine $\ldots \ldots \quad \ldots \ldots \ldots$ & 7,08 & 7,23 & 6,70 & 6,98 \\
\hline Histidine & $3,66^{\mathrm{al}}$ & $2,43^{a}$ & $2,85^{b}$ & $2,67 \mathrm{ab}$ \\
\hline Arginine . . & $4,92^{\mathrm{a}}$ & $4,60^{a}$ & $5,45^{b}$ & $4,93^{\mathrm{a}}$ \\
\hline (1) a, b, c : $\begin{array}{l}\text { voir tableau } 2 . \\
\text { see table } 2 .\end{array}$ & & & & \\
\hline
\end{tabular}




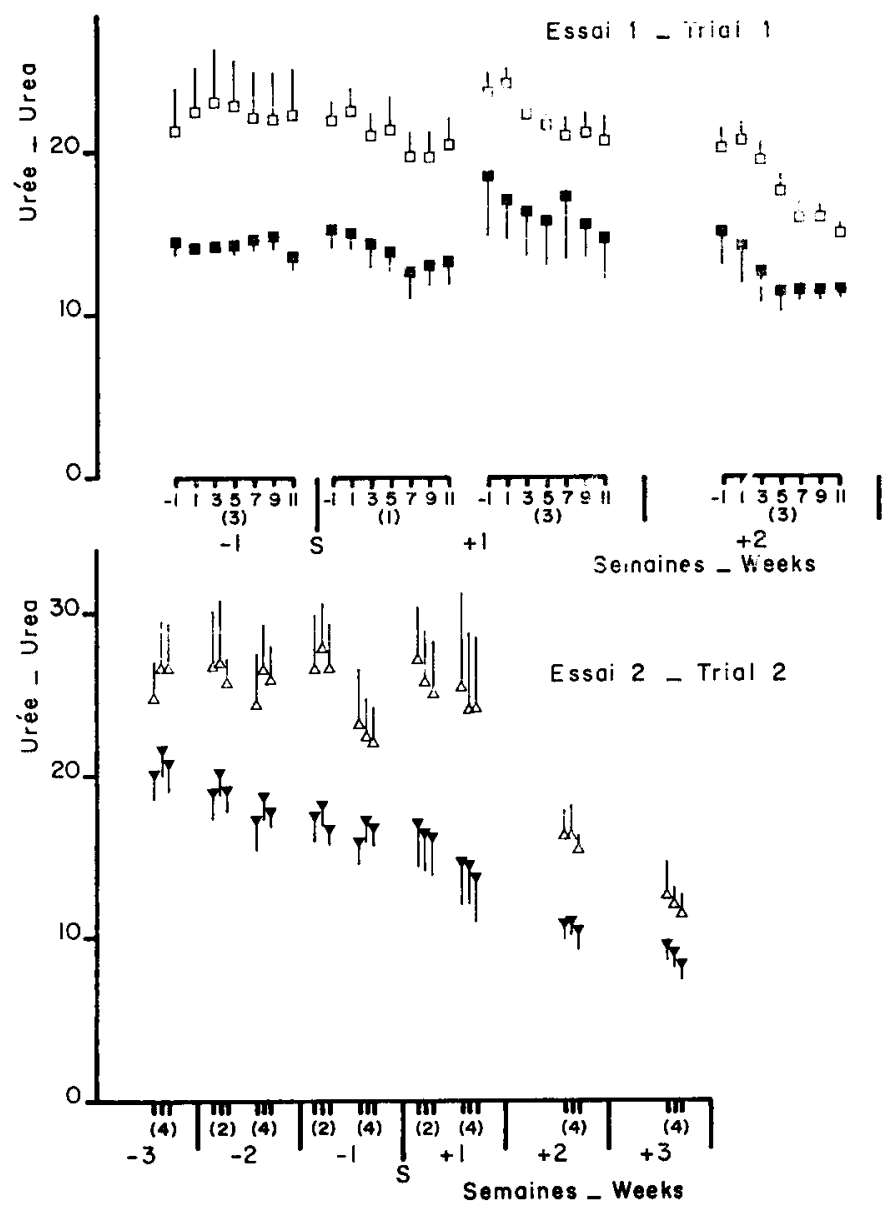

Fig. 2

Evolution de l'urémie ( $\mathrm{mg}$ p. $100 \mathrm{~g}$ ) après l'alimentation du matin, lors des semaines qui précèdent et suivent le sevrage $(S)$.

Variations of blood urea levels ( $m g$ p. $100 \mathrm{~g}$ )

after morning feeding during the weeks before and after weaning (S).

Essai 1: lot A ; $\square$ lot B : valeur moyenne et écart-type de la moyenne ; $-1 \rightarrow 11:$ heures après le repas du matin ; (1), (3) : numéros des jours de prélèvement, chaque semaine ; $-1 \rightarrow+2$ numéros des semaines avant et après le sevrage $(\mathrm{S})$.

Essai $2: \nabla$ lot $C ; \triangle$ lot $D$ : valeur moyenne et écart-type de la moyenne ; (2), (4) : numéros des jours de prélèvement, chaque semaine $;-3 \rightarrow+3:$ numéros des semaines avant et après le sevrage (S).

Trial 1:- group $A ; \square$ group $B:$ mean and standard deviation of the mean; $-1 \rightarrow 11$ hours after morning feeding; (1), (3) : numbers of sampling days on each week; $-1 \rightarrow+2$ : numbers of weeks before and after weaning $(S)$.

Trial 2: $\boldsymbol{\nabla}$ group $C ; \triangle$ group $D:$ mean and standard deviation of the mean; (2), (4) : numbers of sampling days each week $;-3 \rightarrow+3$ : numbers of weeks before and after weaning $(S)$. 

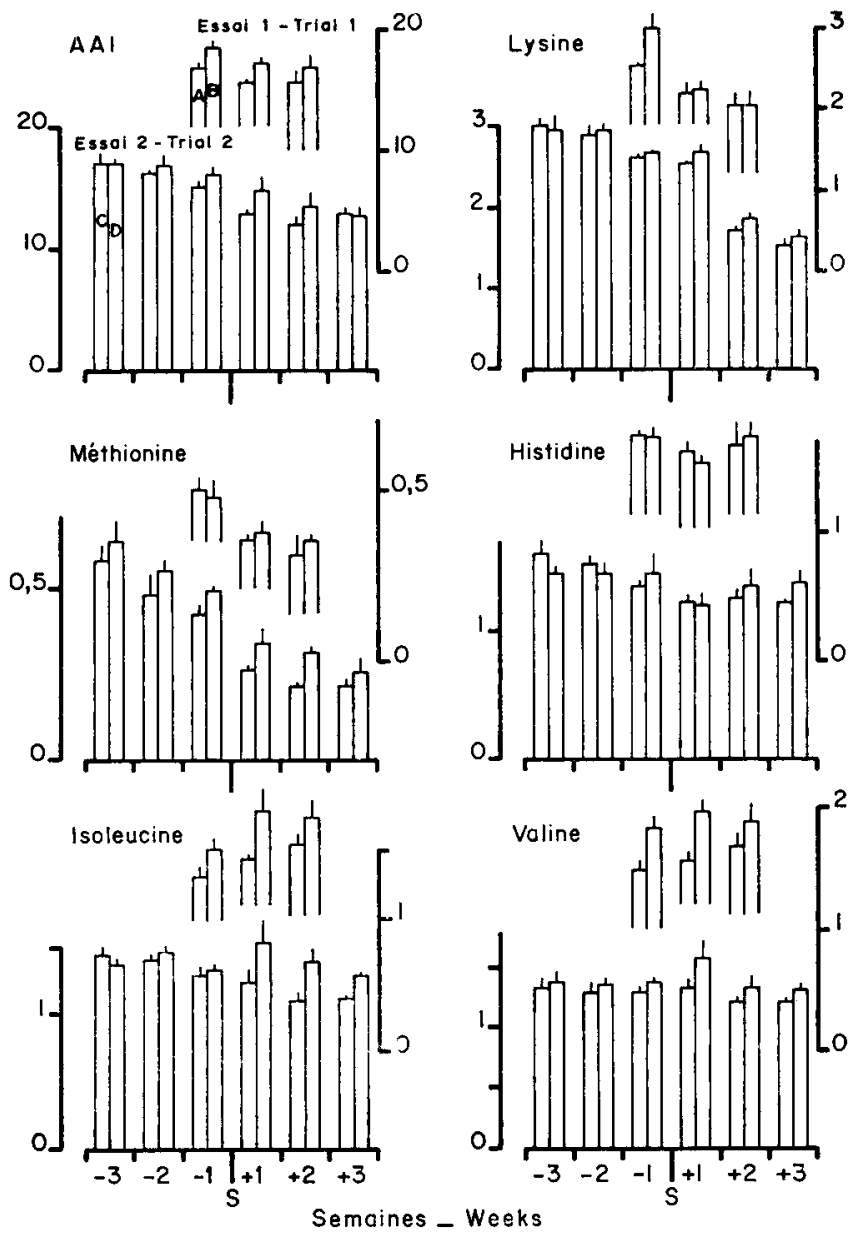

Fig. 3

Evolution des teneurs en acides aminés indispensables libres du sang jugulaire (mg p. $100 \mathrm{~g}$ ) lors des semaines qui précèdent et suivent le sevrage.

Variations in free essential amino acid levels (mg p. $100 \mathrm{~g}$ ) of the jugular blood during the weeks before and after weaning.

AAI : Somme des concentrations en acides aminés indispensables (tryptophane excepté) + tyrosine - Sum of essential amino acid levels (except tryptophan) + tyrosine.

Moyenne et écart-type de la moyenne - Mean and standard deviation of the mean. 

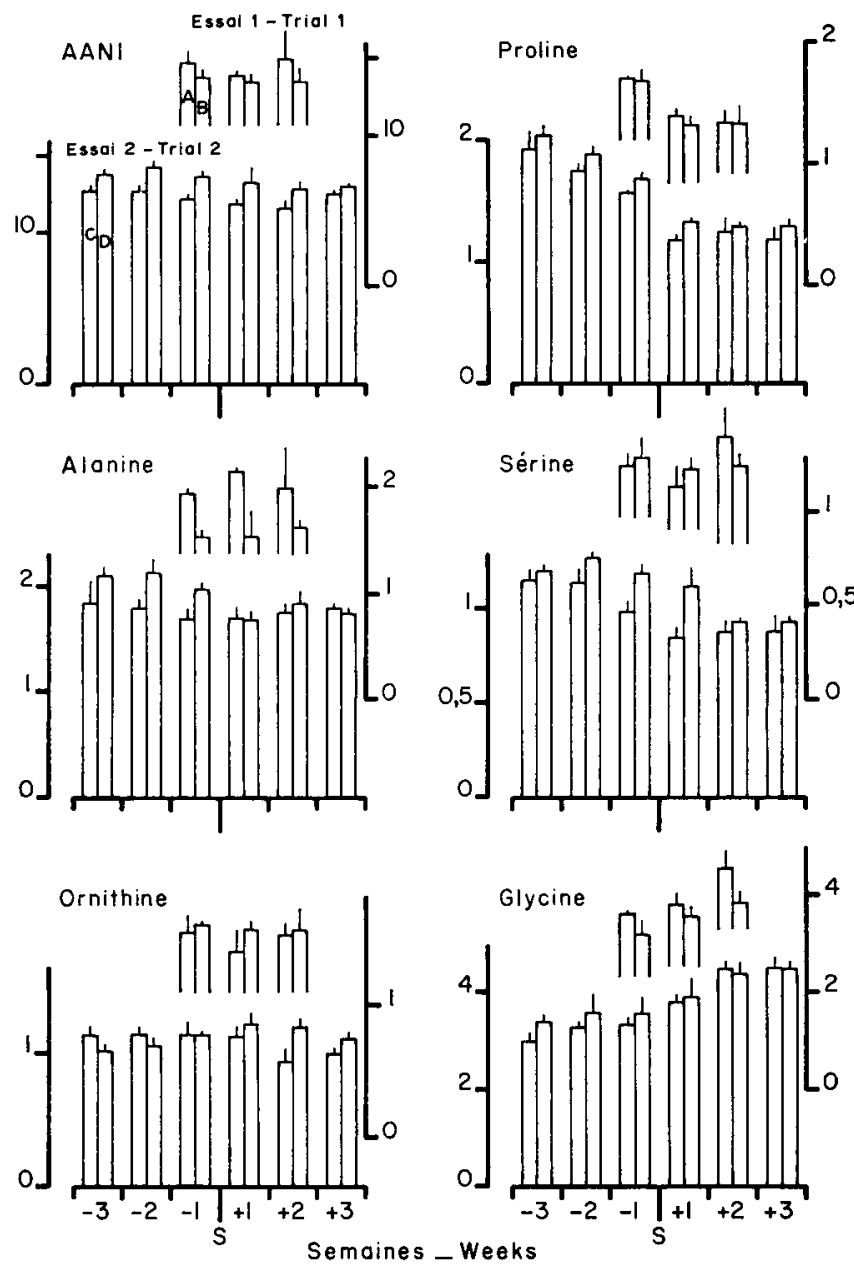

FIG. 4

Evolution des teneurs en acides aminés non indispensables libres du sang jugulaire ( $\mathrm{mg}$ p. $100 \mathrm{~g}$ ) lors des semaines qui précèdent et suivent le sevrage.

Variations in free non essential amino acid levels ( $\mathrm{mg} \mathrm{p} .100 \mathrm{~g}$ ) of the jugular blood during the weeks before and after weaning.

AANI : Somme des concentrations en acides aminés non indispensables - Sum of non essential amino acid levels.

Moyenne et écart-type de la moyenne - Mean and standard deviation of the mean. 
lors des heures précédentes. Cela a été confirmé dans l'essai 2. En outre, d'une semaine à l'autre, l'urémie varie peu jusqu'à la semaine qui suit le sevrage. Toutefois, chez les veaux du lot $\mathrm{C}$, elle a tendance à baisser régulièrement avec l'âge. A partir de la deuxième semaine après le sevrage, elle baisse dans tous les lots. L'urémie des lots $\mathrm{B}$ et $\mathrm{D}$ qui consomment les aliments concentrés riches en matières azotées, est plus élevée que celle des animaux nourris avec les aliments $\mathrm{A}$ et $\mathrm{C}$ qui sont moins bien pourvus; toutefois ces différences ne sont plus significatives lors des semaines +2 et $+3(P>0,05)$.

\section{Aminoacidémie}

Les variations de la somme des teneurs en acides aminés indispensables et semiindispensables dosés (AAI) ainsi que celles des concentrations en certains acides aminés indispensables sont représentées sur la figure 3. Quel que soit l'essai, la somme des teneurs en AAI est plus faible après le sevrage qu'avant. Les concentrations en la plupart des acides aminés indispensables évoluent dans le même sens, comme cela est illustré sur la figure 3 pour la méthionine et la lysine; il en est de même, notamment pour la leucine, la tyrosine et l'arginine (non représentées). En revanche, les teneurs en histidine varient peu et ne sont significativement plus - faibles après le sevrage que dans le sang des génisses du lot $\mathrm{C}$. Chez les veaux qui reçoivent les aliments $B$ et $D$, riches en matières azotées, la somme des teneurs sanguines en acides aminés indispensables (AAI) est plus élevée que chez les veaux nourris avec les aliments $A$ et $C$. Dans l'essai 1, cela tient aux teneurs sanguines élevées en acides aminés à chaîne ramifiée (valine, isoleucine) pendant la période qui suit le sevrage. Dans l'essai 2, les différences portent sur les teneurs en thréonine avant le sevrage et sur celles en thréonine, isoleucine et arginine qui, après le sevrage, sont plus élevées de 29,16 et 14 p. 100 respectivement dans le sang des veaux du lot $\mathrm{D}$ que dans celui de l'autre lot.

L'évolution de la somme des teneurs en acides aminés non indispensables (AANI) et celle des concentrations de certains d'entre eux est représentée sur la figure 4. Dans les 2 essais, la somme des teneurs sanguines en acides aminés non indispensables tend à être plus faible après le sevrage qu'avant (effet non significatif) ; il en est de même pour les teneurs en la plupart des acides aminés non indispensables à l'exception de celles en glycine dans les 2 essais, en alanine dans les lots $\mathrm{A}$ et $\mathrm{C}$ et en ornithine dans le lot $\mathrm{D}$ qui sont voisines ou supérieures à celles observées avant le sevrage. Dans l'essai 1, les sommes des concentrations sanguines en acides aminés non indispensables ne sont pas significativement différentes entre les 2 lots, quelle que soit la semaine étudiée. Dans l'essai 2, elles sont plus élevées chez les veaux du lot $\mathrm{D}$ que chez ceux du lot $\mathrm{C}$. Cette différence traduit principalement celle des teneurs en sérine, proline, ornithine (fig. 4) et citrulline (non représentée).

\section{Discussion}

\section{A. Digestion des matières azotées}

La méthode de prélèvement des contenus d'iléon à l'aide d'une canule simple ne permet pas d'avoir l'assurance de récolter des échantillons représentatifs des 
digesta qui pénètrent dans l'intestin. Cependant, étant donné que les fractions liquides et solides des digesta ont un transit comparable dans l'intestin (Grovum \& WiLliams, 1973), nous avons tenté d'obtenir un échantillon moyen représentatif, par la multiplication des prélèvements (12) et en les répartissant également sur 2 jours pour réaliser, sans perturber l'animal, un échantillon moyen correspondant à celui qui serait constitué par les 12 échantillons récoltés toutes les 2 heures pendant un nycthémère. Cela a été facilité par l'abondance du débit observé lors de chaque prélèvement et décrit chez le mouton par Poncet, IvaN \& LeVEILle (1982). Cette méthode, bien qu'imparfaite, a été retenue de préférence à celle mettant en œuvre des canules réentrantes qui nous aurait peut-être permis une récolte plus représentative des contenus digestifs, car elle paraît moins traumatisante pour des animaux qui vont être soumis au stress du sevrage.

Les variations de la composition en acides aminés des contenus de duodénum au cours du sevrage reflètent des modifications de la nature et des proportions des différentes protéines présentes à ce niveau.

La similitude de composition en acides aminés des contenus de duodénum et de l'aliment d'allaitement avant le sevrage (fig. 1) est la conséquence du fonctionnement de la gouttière œsophagienne qui permet aux protéines lactées de courtcircuiter le rumen. Après le sevrage, la composition de ces contenus se rapproche de celle des protéines bactériennes. La présence de telles protéines est confirmée par l'augmentation de la teneur en acide diaminopimélique des digesta. Le calcul des proportions de protéines alimentaires (lait, orge, tourteau) et bactériennes dans un mélange théorique ayant une composition en acides aminés la plus semblable possible à celle des contenus (distance du $\chi^{2}$ minimale) selon la méthode proposée par Guilloteau, Sauvant \& Patureau-Mirand (1983) indique que la part des protéines microbiennes devient importante (41 à 62 p. 100) après le sevrage (fig. 5). Cela est confirmé par le calcul de cette proportion à partir des tencurs en acide diaminopimélique des contenus et protéines bactériennes. Cette proportion est voisine des valeurs (54 à 64 p. 100) trouvées par LeibHolz (1975) lors des 3 à 5 semaines qui succèdent à un sevrage brutal. Les proportions relativement plus faibles des protéines bactériennes dans les contenus du veau qui consomme l'aliment D, contenant des tourteaux formolés, confirment les observations de Williams \& SMith (1976) qui ont montré chez le veau sevré entre 5 et 8 semaines que la proportion de protéines d'origine microbienne dans les matières azotées entrant dans l'intestin était abaissée lorsque les veaux consommaient un aliment concentré contenant de la caséine traitée au formaldéhyde pour en réduire la dégradabilité dans le rumen. La proportion de protéines de l'orge dans les contenus de duodénum de ce veau, plus faible que dans ceux du veau consommant l'aliment $C$, résulte du fait que pour préparer l'aliment $\mathrm{D}$ des protéines de l'orge ont été remplacées par des protéines de tourteau efficacement protégées de la dégradation dans le rumen.

La stabilité de l'équilibre en acides aminés indispensables et semi-indispensables des protéines des contenus de duodénum au cours du sevrage, alors que la nature et les proportions des protéines présentes à ce niveau du tractus digestif évoluent, ainsi que son indépendance relative vis-à-vis des protéines des aliments concentrés, constatée dans cet essai, peuvent s'expliquer par les particularités de la digestion des matières azotées alimentaires dans le rumen. En effet, à la dégradation ruminale des hordéines qui sont des protéines de l'orge très déséquilibrées en acides aminés indispensables est associée une synthèse de protéines bactériennes mieux équilibrées. De plus, les 
CONTENUS DE DUODENUM _ DUODENAL CONTENTS Aliment $C$ _ Concentrate $C$ Aliment $D$ - Concentrate $D$
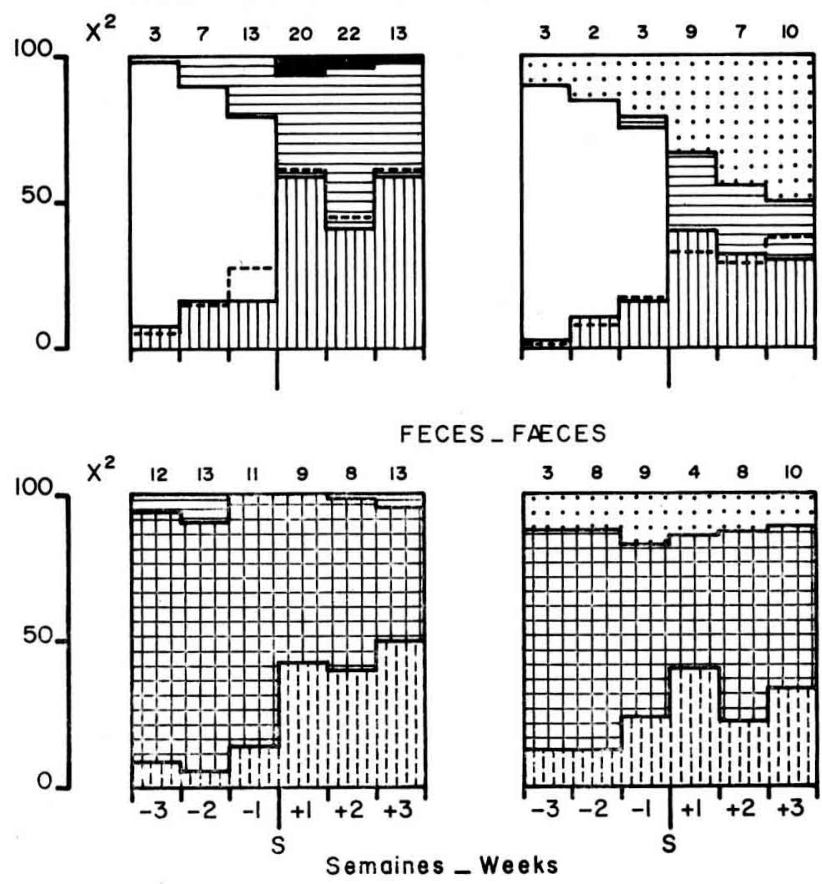

FIG. 5

Evolution de la composition des contenus de duodénum et des fèces en matières azotées alimentaires et bactériennes au cours du sevrage.

Variations in the composition of duodenal contents and faeces of dietary and bacterial proteins during the weaning period.

$\square$ Lait-Milk. WسW Bactéries du rumen (PION \& Fauconneau, 1968) - Rumen bacteria. Protéines ayant la composition en acides aminés des protéines salinosolubles de l'orge (Landry, Moureaux \& Huet, 1972) - Proteins with the same amino acid composition as barley salinosoluble proteins. Hordéines (Lauriere, Charbonnier \& Mosse, 1976) - Hordeins. $\ldots$ Tourteau de soja et de colza traités au formaldéhyde - Formaldehyde treated soyabean and rapeseed meals. Fèces de vcaux préruminants (GRONGNET et al., 1981) - Faeces of preruminant calves. A.til.J Bactéries de fèces de porc (MASON, JUST \& BECH-ANDERSEN, 1976) - Faecal bacteria from pigs.

-.-- Teneur en protéines bactériennes calculéc à partir de la concentration en acide diaminopimélique des contenus et des bactéries du rumen (LING \& BUTTERY, 1978) - Bacterial protein content estimated from the $D A P$ levels in duodenal contents and in rumen bacteria. $\chi^{2}$ calculé entre la composition en acides aminés observée et celle estimée en fonction des proportions des diverses protéines dans les digesta (Guilloteau, Sauvant \& Patureau-Mirand, 1983) - $\chi^{2}$ calculated between the measured amino acid composition in digesta and that estimated from the percentages of each protein. 
protéines de l'orge qui ont résisté à la dégradation (PSO) et les protéines des tourteaux ont un équilibre en acides aminés indispensables et semi-indispensables relativement comparable. Il en résulte qu'avec les 2 aliments, les matières azotées des contenus du duodénum gardent un équilibre en acides aminés indispensables et semi-indispensables relativement constant qui, par ailleurs, cst voisin de celui qui paraît le plus favorable à la satisfaction des besoins du veau préruminant (tabl. 3).

L'étude de l'évolution de la composition des fèces montre que l'augmentation de la consommation d'aliments solides (semaines - 2 à +3 ) s'accompagne d'un accroissement de la proportion de protéines bactériennes (fig. 5). Cela pourrait résulter du fait que la plus faible digestibilité de ces aliments solides comparée à celle du lait favorise le développement d'une importante flore microbienne dans l'intestin (MASON et al., 1977) et/ou à la présence de protéines des bactéries du rumen non digérées. Il est difficile de savoir si l'absence apparente de protéines de l'orge dans les fèces est due à l'activité des enzymes intestinales ou à l'activité combinée des enzymes digestives et des bactéries du gros intestin. En revanche, la présence supposée de protéines des tourteaux à ce niveau traduit leur résistance à l'action des enzymes. digestives et microbiennes.

\section{B. Facteurs de variations de l'urémie et de l'aninoacidémie}

\section{Urémie}

L’influence de la quantité de matières azotées ingérées ou du taux protéique de l'aliment sur ce paramètre a déjà été décrite chez l'agneau préruminant (PÁtureauMirand et al., 1977) ou ruminant (ChAmpredon et al., 1978) ainsi que chez le veau ruminant (Williams \& SмITh, 1976). La baisse de l'urémie au cours du sevrage peut être reliée à la réduction des quantités de PDI ingérées (KouAme et al., 1984); puis, lorsque ces dernières augmentent à nouveau après le sevrage, cette baisse témoignerait d'une réduction du catabolisme des acides aminés et d'un recyclage intense de l'urée sanguine, résultant de l'augmentation des quantités d'aliments solides et d'énergie métabolisable ingérées (Kouame et al., 1984). Cela est confirmé par le signe des coefficients dans la relation qui peut être établie entre l'urémie $(\mathrm{mg} \mathrm{p} .100 \mathrm{ml})$, les PDI $\left(\mathrm{g} / \mathrm{kg}^{0, \pi}, \mathrm{j} / \mathrm{j}\right)$ et l'énergie métabolisable $\left(\mathrm{EMI} \mathrm{kcal} / \mathrm{kg}^{0,75} / \mathrm{j}\right)$ ingérées sur l'ensemble des 2 essais :

$$
\text { Urémie } \left.\left.\left.=4.21^{\prime 1}\right)^{\mathrm{PDI}}-0,26^{\prime 1}\right) \mathrm{EMI}+31,94^{\prime 1}\right)^{2} \mathrm{r}^{2}=0,79
$$

\section{Aminoacidémie}

Les variations des teneurs en acides aminés libres du sang sont comparables à celles décrites par LeibHOLz (1965) chez des veaux sevrés brutalement à 5 semaines. La baisse des teneurs en la plupart des acides aminés pendant le sevrage paraît correspondre en partie à la réduction de la quantité de PDI ingérée. L'augmentation de la glycémie, décrite elle aussi par Leibholz (1965) pourrait résulter de l'augmentation de la quantité de glycine absorbée du fait de l'enrichissement des contenus de duodénum en ce composé (tabl. 2) et/ou de l'accroissement du métabolisme de la paroi du rumen (Boila \& Milligan, 1980). L'absence de variations des teneurs en

(1) Coefficients significativement différents de zéro $(\mathbf{P}<\mathbf{0 , 0}$ I). 


\section{Tableau 5}

Relations entre les teneurs en acides aminés libres du sang (mg p. $100 \mathrm{~g}$ ),

les quantités d'acides aminés absorbables (1) $\left(\mathrm{g} / \mathrm{kg}^{\mathrm{o}, 75 / j}\right)$

et d'énergie métabolisable (Mcal/kgo,75/j) ingérées.

Relationships between blood levels of free amino acids ( $m g$ p. $100 \mathrm{~g}$ ),

intake of absorbable (1) amino acids $\left(\mathrm{g} / \mathrm{kg}^{0.75} / \mathrm{d}\right)$

and intake of metabolizable energy (Mcal/ $\mathrm{kg}^{0.75 / \mathrm{d}}$ ).

\begin{tabular}{|c|c|c|c|c|}
\hline $\begin{array}{l}\text { Acides aminés } \\
\text { Amino acids }\end{array}$ & $\begin{array}{c}\text { Quantités } \\
\text { absorbables } \\
\text { Absorbable } \\
\text { amounts (1) }\end{array}$ & $\begin{array}{c}\text { Energie } \\
\text { métabolisable } \\
\begin{array}{c}\text { Metabolizable } \\
\text { energy }\end{array}\end{array}$ & $\begin{array}{l}\text { Constante } \\
\text { Constant }\end{array}$ & $\mathrm{R}^{2}(2)$ \\
\hline Thréonine & $7,323 * *$ & $-17,424 * *$ & $1,847 * *$ & 0,864 \\
\hline Valine ...... & 1,064 & $-5,339$ & $3,144 * *$ & 0,295 \\
\hline Méthionine ... & $2,367 * *$ & $-2,685^{*}$ & $0,514 * *$ & 0,878 \\
\hline Isoleucine $\ldots \ldots$ & $1,401 *$ & $-3,867^{*}$ & $1,500 * *$ & 0,561 \\
\hline Leucine & $1,742 * *$ & $-8,880^{* *}$ & $2,428^{* * k}$ & 0,857 \\
\hline Tyrosine & $2,277 * *$ & $-4,296^{* * *}$ & $0,994 * *$ & 0,948 \\
\hline Phénylalanine & $0,832 * *$ & $-1,919^{* *}$ & $1,075 * *$ & 0,621 \\
\hline Lysine & $4,606 *$ & $-17,361^{* *}$ & $2,848 * *$ & 0,971 \\
\hline Histidine & $1,688^{*}$ & $-0,957$ & $1,200 * *$ & 0,681 \\
\hline Arginine . & $-0,002$ & 2,605 & 0,625 & 0,135 \\
\hline Ac. aspartique & $-0,209$ & 1,520 & $0,243 * *$ & 0,218 \\
\hline Sérine $\ldots . . .$. & $1,598^{* * *}$ & $-4,994 * *$ & $1,275 * *$ & 0,822 \\
\hline Ac. glutamique & $0,309 *$ & $-2,354$ & $1,731 * *$ & 0,478 \\
\hline Proline & $1,244 * *$ & $-3,737 * *$ & $1,508^{* *}$ & 0,851 \\
\hline Glycine & $7,596 * *$ & $-8,739^{* *}$ & $3,033^{* *}$ & 0,916 \\
\hline Alanine $\ldots \ldots \ldots$ & $-1,056$ & 2,693 & $1,775 * *$ & 0,176 \\
\hline
\end{tabular}

$* \quad \mathbf{P}<0,05$.

** $\quad \mathbf{P}<0,01$.

(1) Quantités de PDI ingérées $\left(\mathrm{g} / \mathrm{kg}^{\mathrm{0}},{ }^{75} / \mathrm{j}\right) \times$ teneurs en acides aminés des matières protéiques des contenus de duodénum (p. 100 des acides aminés dosés).

Amounts of PDI ingested $\left(\mathrm{g} / \mathrm{kg}^{0.75} / \mathrm{d}\right) \times$ amino acid concentrations of proteins from the duodenal contents ( $p .100$ sum of amino acids).

(2) Pourcentage de la somme des carrés des écarts des teneurs en acides aminés libres à leurs valeurs moyennes expliqué par la régression.

Fraction of the sum of squares of deviations of blood levels of free amino acid from their means imputable to the regression. 
acides aminés ramifiés pendant l'essai 2 ou même l'augmentation temporaire de celles en valine et isoleucine dans l'essai 1 alors que les PDI ou ces composés sont fournis dans l'intestin en plus faibles quantités lors de la semaine +1 , cst la conséquence de la carence énergétique subie par ces animaux pendant cette période. En effet, ces composés tendent à s'accumuler dans le sang lorsque l'apport azoté est excessif compte tenu des quantités d'énergie ingérées. Ces liaisons entre les teneurs en acides aminés libres du sang, quantités d'énergie métabolisable ingérée et quantités d'acides aminés absorbés ont été précisées pour chaque acide aminé lors de l'essai 2 où les teneurs en acides aminés libres varient suffisamment. Les régressions calculées à partir des valeurs moyennes de l'aminoacidémie, des quantités d'acides aminés absorbables ingérées (produit des PDI ingérées et de la composition en acides aminés des contenus de duodénum prélevés sur le veau recevant le même régime) et des quantités d'énergie métabolisable ingérées observées chaque semaine sont significatives pour la plupart des acides aminés (tabl. 5). Elles indiquent que les teneurs en thréonine, méthionine, leucine, tyrosine, lysine, sérine, proline et glycine libres du sang augmentent lorsque s'accroît le flux de ces composés à l'entrée de l'intestin, comme cela est observé chez les monogastriques (PION, 1976). En revanche, elles diminuent quand augmentent les quantités d'énergie métabolisable ingérées du fait de l'utilisation plus intense de ces acides aminés pour accroître la masse des protéines corporelles ce qui se manifeste par l'élévation du gain de poids journalier (Kounme et al., 1984). Cela montre ainsi, que, pendant cette période, les teneurs en acides aminés libres du sang dépendent de 2 facteurs évoluant de façon comparable mais qui ont des effets contraires : l'apport des acides aminés par la digestion dans l'intestin et l'augmentation de la masse des protéines corporclles favorisées par celle de la quantité d'énergic ingérée. Leur interprétation peut donc être délicate lorsque ces facteurs ne sont pas contrôlés.

Le maintien des teneurs sanguines en lysine et en méthionine libres à de faibles valeurs après le sevrage alors que les quantités de lysine et de méthionine absorbables ingérées s'accroissent dans les 2 essais, confirment l'hypothèse de LEIBHOLz (1975) et les résultats de Guilhermet et al. (1983) selon laquelle la lysine et la méthionine seraient les acides aminés indispensables limitants pour la croissance du veau après le sevrage.

\section{Conclusion}

L'évolution de la composition protéique des contenus de duodénum pendant la période du sevrage montre que la production de protéines microbiennes dans le rumen se développe rapidement lorsque des aliments solides sont ingérés. Cela confirme les conclusions de l'article précédent concernant la mise en place précoce des fermentations microbiennes des aliments solides, à l'origine de l'augmentation des teneurs plasmatiques en acétate et $\beta$ hydroxybutyrate. L'équilibre en acides aminés indispensables des contenus de duodénum semble relativement favorable pendant toute cette période bien que les proportions et la nature des diverses protéines présentes à ce niveau, varient considérablement. Toutefois, du fait des bas niveaux d'ingestion lors des semaines qui précèdent ou suivent immédiatement le sevrage, une carence générale en matières azotées peut être observéc lorsque les aliments concentrés ont un taux protéique bas comme l'aliment C. L'addition 
de protéines de tourteaux traités au formaldéhyde permet de fournir un supplément d'acides aminés, notamment de lysine et de méthionine qui paraissent être les acides aminés limitants pendant cette période, dans la mesure où le besoin énergétique est satisfait. En effet, le niveau d'apport énergétique est le principal facteur limitant de l'utilisation des acides aminés pendant toute cette période du sevrage puisque les variations de l'aminoacidémie sont étroitement liées à celles de la quantité d'énergie ingérée. Ces 2 essais qui ont fourni des indications sur la digestion et l'utilisation métabolique de l'énergie et de l'azote au cours du sevrage, ont permis de préciser certains facteurs limitants de l'utilisation des aliments solides qu'il convient de prendre en considération dans la conception d'aliments concentrés destinés à l'alimentation de jeunes veaux en cours de sevrage.

\section{Remerciements}

Nous tenons à remercier M. J. Lefaivre pour la pose des canules du duodénum.

\section{Summary \\ Calf nutrition during the weaning period \\ II. - Some aspects of protein digestion and metabolism}

Variations in urea and free amino acid levels in the jugular blood of the 16 French Pie Noir calves used in both trials already described (KoUAME et al., 1984) were studied during the week before weaning and 2 weeks thereafter (trial 1) and during the 3 weeks before weaning and the 3 weeks thereafter (trial 2). The calves were weaned when they were 6 weeks old. During trial 2, the amino acid compositions of duodenal contents and of faeces were also determined in 2 male calves fitted with a single cannula in the proximal duodenum.

The amino acid composition of the duodenal contents which was similar to that of milk before weaning became more similar to that of rumen bacteria after weaning (tabl. 2 and fig. 1). Hordeins seemed to be highly degraded in the stomach. Inversely, the proteins from treated soyabean and rapeseed meal appeared to be slightly degraded (fig. 5) and would be able to provide a larger amount of amino acids to the tissues of the calves fed diets containing those proteins. Blood urea levels which remained nearly constant until one week after weaning, decreased thereafter (fig. 2). They were higher in the blood of the calves fed the concentrates with the higher protein content (B and D). Their variations could be related to the intakes of PDI and metabolizable energy. Blood-free essential amino acids decreased during the weaning period, except valine and isoleucine. In both trials, they were higher in the blood of the calves fed the concentrates containing the higher protein content (fig. 3). Free lysine, methionine, threonine, leucine and tyrosine in blood were closely related to the estimated flows of these amino acids into the duodenum and to the intake of metabolizable energy. Lysine and methionine seemed to be the main limiting amino acids during the weaning period. Variations in free proline and free glycine in the blood (fig. 4) may be related to the variations in duodenal contents of these 2 amino acids during this period.

Key words : weaning, calf, dietary protein, digestion, protein metabolism. 


\section{Références bibliographiques}

Boila R.J., Milligan L.P., 1980. The in vitro synthesis of glycine by rumen papillae. Can. J. Anim. Sci., 60, 43-51.

Champredon C., Pion R., Martin-Rosset W., 1978. Influence du taux azoté de la ration sur l'aminoacidémie libre de l'agneau. C.R. Soc. Biol., 172, 927-933.

Guilloteau P., Sauvant D., Patureau-Mirand P., 1983. Methods of comparing amino acid composition of proteins : application to undigested proteins in the preruminant calf. Ann. Nutr. Metabolism, 27, 457-469.

Grongnet J.F., Patureau-Mirand P., Toullec R., Prugnaud J., 1981. Utilisation des protéines du lait et du lactosérum par le jeune veau préruminant. Influence de l'âge et de la dénaturation des protéines de lactosérum. Ann. Zootech., 30, 443-464.

Grovum W.L., Williams V.J., 1973. Rate of passage of digesta in sheep. 3-Differential rates of passage of water and dry matter from the reticulo-rumen, abomasum and caecum and proximal colon. Br. J. Nutr., 30, 231-240.

Guilhermet R., Alrhamoun W., Toullec R., Prugnaud J., 1983. Influence de la supplémentation postruminale en lysine sur l'aminoacidémie et les teneurs plasmatiques en glucose et en urée chez le veau ruminant. Sci. Agron. Rennes, 2, 62-70.

I.N.R.A., 1978. Alimentation des Ruminants. Ed. I.N.R.A. Publications, Versailles, 597 p.

Kouame K.G., Troccon J.L., Patureau-Mirand P., Journet M., Pion R., 1984. Nutrition des veaux au cours du sevrage. 1. Evolution de la consommation d'aliments et des concentrations sanguines et divers métabolites énergétiques. Ann. Zootech., 33, 427-444.

Landry J., Moureaux T., Huet J.C., 1972. Extractibilité des protéines du grain d'orge : dissolution sélective et composition en acides aminés des fractions isolées. Bios., 8, 281-292.

Lauriere M., Charbonnier L., Mosse J., 1976. Nature et fractionnement des protéines de l'orge extraites par l'éthanol, l'isopropanol et le n-propanol à des titres différents. Biochimie, 58, 1235-1245.

Lebart L., Fenelon J.P., 1973. Statistique et informatique appliquées. Dunod, Paris, 222-251.

LEIBHolz J., 1965. The effect of age and dietary protein source on free amino acids, ammonia and urea in the blood plasma of the calf. Aust. J. Agric. Res., 17, 236-246.

Leibrolz J., 1975. The development of ruminant digestion in the calf : the digestion of barley and soyabean meal. Aust. J. Agric. Res., 26, 1081-1091.

LiNg J.R., ButTERY P.J., 1978. The simultaneous use of ribonucleic acid, 35S, 2-6 diaminopimelic and 2-aminoethylphosphonic acid as markers of microbial nitrogen entering the duodenum. Br. J. Nutr., 39, 165-179.

Mason V.C., Just A., Bech-Andersen S., 1976. Bacterial activity in the hindgut of pigs. 2 . Its influence on the apparent digestibility of nitrogen and amino acids. Z. Tierphysiol. Tierernähr. Futtermittelk., 36, 310-324.

Mason V.C., Narang M.P., Ononiwu J.C., Kessank P., 1977. The relationship between nitrogen metabolism in the hing-gut and nitrogen excretion. In : Tamminga S., Protein Metabolism and Nutrition, 61-63. Fédération Européenne de Zootechnie, publication $\mathrm{n}^{\circ} 22$.

MziK J., Hogan J.P., Lindsay J.R., Davis P., 1978. A rapid chromatographic determination of diaminopimelic acid with lithium citrate buffers. J. Chromatogr., 152, 269-271.

Patureau-Mirand P., Prugnaud J., Arnal M., Pion R., 1973. Métabolisme de la méthionine ${ }^{35} \mathrm{~S}$ chez le veau préruminant. Ann. Biol. Anim. Biochim. Biophys., 13, 565-585.

Patureau-Mirand P., Prugnaud J., Bayle G., Pion R., 1980. Influence of dietary histidine level on histidine metabolism in the preruminant calf. In OsLage H.J., RoHr K., Protein Metabolism and Nutrition, 1, 356-361. Fédération Européenne de Zootechnie, publication $n^{\circ} 27$.

Patureau-Mirand P., Theriez M., Prugnaud J., Pion R., 1977. Influence du taux protéique et de la composition en acides aminés de l'aliment d'allaitement sur l'aminoacidémie de l'agneau préruminant. Ann. Zootech., 26, 315-328. 
Patureau-Mirand P., Toullec R., Paruelle J.L., Prugnaud J., Pion R., 1974. Influence de la nature des matières azotées des aliments d'allaitement sur l'aminoacidémie du veau préruminant. Ann. Zootech., 23, 343-358.

Pawlak M., Pion R., 1968. Influence de la supplémentation des protéines de blé par des doses croissantes de lysine sur la teneur en acides aminés libres du sang et du muscle du rat en croissance. Ann. Biol. Anim. Biochim. Biophys., 8, 517-530.

PION R., 1976. Dietary effects and amino acids in tissues. In : Cole D.J.A., Boorman K.N., Buttery P.J., Lewis D., Neale R.J., Swan H., Protein Metabolism and Nutrition, 259-277, Butterworths.

Pion R., De Belsunce C., Fauconneau G., 1963. Composition en acides aminés de quelques aliments. Ann. Biol. Anim. Biochim. Biophys., 3 (h.s.l.), 11-18.

Pion R., Fauconneau G., 1968. Les ressources mondiales actuelles et futures en protéines disponibles pour l'alimentation de l'homme et leurs possibilités d'utilisation. In : Isotopes studies on the nitrogen chain, 3-59, International Atomic Energy Agency. Vienne.

Poncet C., IVan M., Leveille M., 1982 Electromagnetic measurements of duodenal digesta flow in cannulated sheep. Reprod., Nutr., Develop., 22, 651-660.

Poncet C., Rayssiguier Y., 1980. Effect of lactose supplement on digestion of lucerne hay by sheep. 1. Sites of organic matter and nitrogen digestion. Br. J. Nutr., 51, 180-185.

Prugnaud J., Pion R., 1976. Dosage des acides aminés dans les aliments. Journée de Biochimie : l'analyse des acides aminés. Beckman. Paris, 23 p.

Snedecor G.W., Cochran W.G., 1971. Méthodes statistiques. Association de Coordination Technique Agricole. Paris, 649 p.

Williams A.P., SMith R.H., 1976. Nitrogen metabolism in calves. Effect of giving different amounts of dietary casein with and without formaldehyde treatment. Br. J. Nutr., 36, 199-209. 